\title{
STUDIES ON THE MODE OF ACTION OF SODIUM PENTOBARBITAL IN BLOCKING OVULATION IN RATS
}

\author{
A. ZOLOVICK AND A. P. LABHSETWAR* \\ Worcester Foundation for Experimental Biology, \\ Shrewsbury, Massachusetts 01545, U.S.A.
}

(Received 15th August 1974)

Barbiturates, notably sodium pentobarbital (Nembutal), have provided a useful tool for studying the neuroendocrine mechanism mediating ovulation. Everett \& Sawyer (1950) first used barbiturates to confirm the existence of the 'critical period' which they had earlier detected by using atropine and Dibenamine, an $\alpha$-adrenergic blocking agent (Everett, Sawyer \& Markee, 1949). It has been generally assumed that pentobarbital (PB) and related barbiturates interfere with ovulation by acting on the central nervous system. Hagino (1969) reported inhibition of PMSG-induced ovulation in immature rats by PBinjected directly into the hypothalamus although the pituitary was not excluded as a possible site of action of the drug. Cross \& Dyer (1971) reported reduced unit activity of hypothalamic neurons following intravenous injection of subanaesthetic doses of sodium methohexitone (Brietal: Eli Lilly Co. Ltd) but response to urethane was variable. Using a somewhat different experimental design involving progesterone-induced ovulation, a direct action of $\mathrm{PB}$ on the ovary has been implicated in inhibition of ovulation by this drug (Meyer, Karavolas, Klausing \& Norgard, 1971; Karavolas, Gupta \& Meyer, 1972). These authors have proposed that $\mathrm{PB}$ inhibits ovulation by markedly altering the secretory patterns of progestagens from the ovary. This, in effect, alters the optimal steroid environment required for ovulation. The different results obtained by Hagino (1969) and Meyer et al. (1971) could be due to slight differences in the experimental design. We therefore decided to distinguish between the central and peripheral sites of action of $\mathrm{PB}$ by studying the effects of intracerebrally administered $\mathrm{PB}$ on ovulation in the experimental model used by Meyer et al. (1971), i.e. immature rats primed with PMSG and given a single injection of progesterone to evoke an ovulatory response. We also attempted to ascertain whether the production of general anaesthesia which accompanies the treatment is a necessary condition for inhibition of ovulation by PB in view of several recent reports that general anaesthetics can modify gonadotrophin secretion (Neill, 1970; Ajika, Kalra, Fawcett, Krulich \& McCann, 1972).

Immature rats of the Sprague-Dawley strain (Charles River Co., Wilmington,

* Correspondence: Dr A. P. Labhsetwar, Division of Biology, Kansas State University, Manhattan, Kansas 66506, U.S.A. 
Mass.) and weighing between 65 and $70 \mathrm{~g}$ were received in the laboratory when 26 days old. They were housed in groups of four or five to a cage with the room temperature maintained at $71^{\circ} \mathrm{F}$ and lights on from 06.00 to 18.00 hours. Free access to standard food and tap water was provided.

Rats received a single subcutaneous (s.c.) injection ( $5 \mathrm{i}$.u. in $0.1 \mathrm{ml}$ saline at 11.00 hours) of PMSG (Equinex: Ayerst) at 29 days of age. On the following day, at 11.00 hours, $1 \mathrm{mg}$ progesterone was injected s.c. in $0.2 \mathrm{ml}$ corn oil. The animals were killed $24 \mathrm{hr}$ later and the oviducts were searched for ova. For microinjection of $\mathrm{PB}$, the powder (Sigma Co.) was dissolved in a vehicle composed of propylene glycol:saline $(1: 1, \mathrm{v} / \mathrm{v})$. The $\mathrm{pH}$ of this solution was found to be $7 \cdot 6$, and therefore, the $\mathrm{pH}$ of the vehicle for control injections was adjusted to 7.6 by the addition of $1 \mathrm{~N}-\mathrm{NaOH}$.

Rats were anaesthetized with ether at various times after progesterone injection as indicated in Table 1 and placed in a standard Kopf stereotaxic instrument. A stainless steel cannula (27-gauge) attached to a $50-\mu l$ syringe was then directed into the anterior hypothalamic area using the stereotaxic atlas of Konig \& Klippel (1963). The injections into this area were given bilaterally using the following coordinates: anterior-posterior $=+6 \cdot 2$, lateral $= \pm 0 \cdot 5$, and vertical $=-3.0 \mathrm{~mm}$. The pituitary injections were made by using a transauricular approach, thus avoiding the passage of a cannula through and migration of material into the hypothalamus.

At autopsy, approximately $48 \mathrm{hr}$ after PMSG injection, both oviducts were removed and searched for ova. Brains were removed and examined to determine the location of the cannula tracts, as already described (Labhsetwar \& Zolovick, 1973). The skulls of animals given intrapituitary injections of $P B$ were examined and only those animals showing clear evidence of such injections, i.e. a hole on the side of the pituitary, were included. Of the eight animals used in this group, two were rejected due to misplacement of the cannula.

All results are presented in Table 1. Injection of progesterone following priming with PMSG induced a full ovulatory response in $95 \%$ of the rats (Group 1). The yield of ova $(9 \cdot 9 \pm 0.5)$ was comparable to that normally found in adult rats on the day of oestrus. Any decrease in the incidence of ovulation observed in the treated groups can, therefore, be confidently attributed to the treatment rather than to inability of the animal to respond to the PMSGprogesterone regimen. The microinjection of vehicle at 14.00 hours, i.e. $3 \mathrm{hr}$ after progesterone injection, failed to interfere with ovulation (Group 2), but a similar injection of $\mathrm{PB}$ at this time blocked ovulation in $91 \%$ to $100 \%$ of the rats (Groups 5 and 6). Administration of PB before 14.00 hours (Groups 3 and 4) proved essentially ineffective. After 14.00 hours, the effectiveness of $P B$ to inhibit ovulation decreased progressively from $77 \%$ at 15.00 hours (Group 7) to $10 \%$ by 17.00 hours (Group 9 ). Thus, the most effective time for PB to interfere with progesterone-induced ovulation was around 14.00 hours (Group 6) which corresponds to the onset of the 'critical period' under our conditions as determined by intraperitoneal administration of $45 \mathrm{mg} \mathrm{PB} / \mathrm{kg}$ (A. Zolovick and A. Labhsetwar, unpublished data). Injection of $\mathrm{PB}$ into the cerebral cortex (Group 10) or into the anterior pituitary (Group 11) at 14.00 hours proved largely ineffective (Table 1). Inhibition of ovulation by PB injection into the 


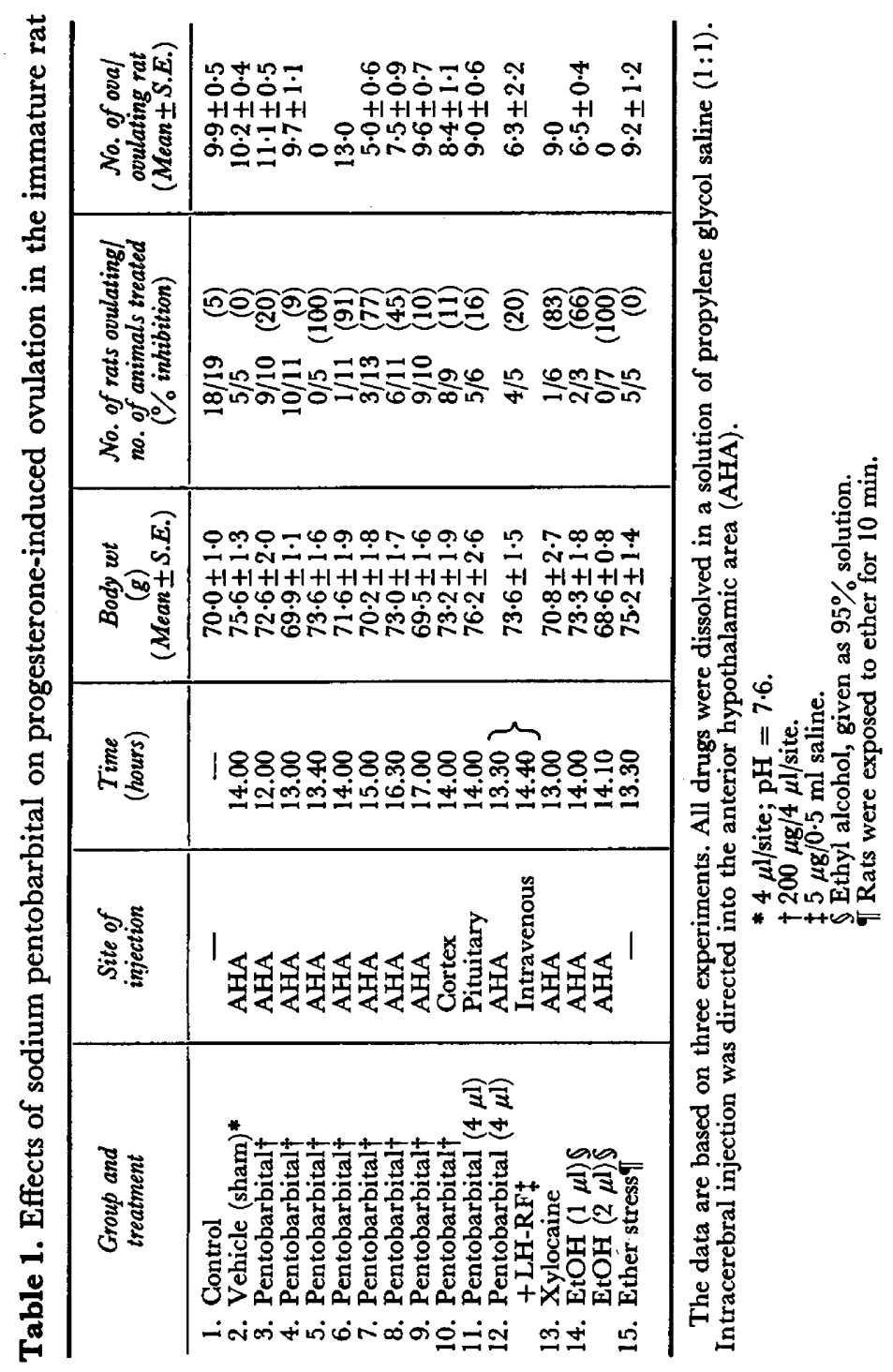


anterior hypothalamic area at 14.00 hours could be readily reversed by intravenous injection of $5 \mu \mathrm{g}$ synthetic LH-RF in saline (Group 12).

Injection of $\mathrm{PB}$ into the area produced a transient anaesthesia of 8- to 12-min duration. Ether anaesthesia of a similar duration proved ineffective in inhibiting ovulation (Group 15). By contrast, xylocaine hydrochloride (Xylocaine: Astra, Worcester, Mass.) (Group 13) or 95\% ethyl alcohol (Group 14), both local anaesthetics, were quite effective in interfering with ovulation following their application to the anterior hypothalamus. None of the treatments caused significant loss in body weight (Table 1).

Our results demonstrate that injections of $\mathrm{PB}$ into the anterior hypothalamus interfere with progesterone-induced ovulation in rats primed with PMSG. A similar injection of vehicle alone failed to produce the effect and the same injection of $\mathrm{PB}$ either directly into the anterior pituitary or into the cerebral cortex was largely ineffective. These results imply that $\mathrm{PB}$ was selectively acting at the hypothalamic level to interfere with ovulation. Diffusion of material from the injection area into the portal vessels within the median eminence and from there to the anterior pituitary cannot account for the interference with ovulation as a direct injection of $\mathrm{PB}$ into the pituitary was not effective. Further, intravenous injection of synthetic LH-RF readily reversed the PB block. It appears, therefore, that PB exerts its inhibitory effect either by interfering with the discharge of LH-RF into the portal circulation and blocking the secretion of ovulating hormone and/or by inhibiting the synthesis of LH-RF in the hypothalamus. The results exclude the ovary as a site of action of PB in interfering with ovulation.

The importance of the sedative or anaesthetic effect of barbiturates in blocking ovulation has not been thoroughly studied. In the present study, ether anaesthesia for the same duration as that elicited by injection of PB into the anterior hypothalamus failed to interfere with ovulation while the two structurally dissimilar local anaesthetics used, which had no demonstrable general anaesthetic effect following intrahypothalamic injection, were as effective as $\mathrm{PB}$ in blocking ovulation. This suggests that the ability of a compound to induce general anaesthesia is unrelated to its ability to interefere with ovulation, but that the ability to induce local anaesthesia within the hypothalamus, and thus presumably to interfere with the neural transmission or the discharge of LH-RF, appears to be crucial in blocking ovulation.

This study was partly supported by a grant from the Ford Foundation. We thank the Abbott Laboratory for the generous gift of a synthetic decapeptide (Gn-RH) and Ayerst Co., N.Y., for Equinex.

\section{REFERENCES}

Ajika, K., Kalra, S. P., Fawcett, C. P., Krulich, C. \& McCann, S. M. (1972) The effect of stress and Nembutal on plasma levels of gonadotropins and prolactin in ovariectomized rats. Endocrinology, 90, 707-715.

Cross, B. A. \& Dyer, R. G. (1971) Unit activity in rat diencephalic islands-the effect of anaesthetics. J. Physiol., Lond. 212, 467-481.

Everetr, J. W. \& SAWYer, C. H. (1950) A 24-hour periodicity in the "LH release apparatus" of the female rats, disclosed by barbiturate sedation. Endocrinology, 47, 198-218. 
Everett, J. W., Sawyer, C. H. \& Markee, J. (1949) A neurogenic timing factor in control of the ovulatory discharge of luteinizing hormone in the cyclic rat. Endocrinology, 44, 234-250.

Hagino, N. (1969) The hypothalamic time sequence controlling gonadotropin release in the immature female rat. Neuroendocrinology, 5, 1-9.

Karavolas, H., Gupta, C. \& Meyer, R. K. (1972) Steroid biosynthesis and metabolism during phenobarbital (PB) block of PMS-induced ovulation in immature rats. Endocrinology, 91, 157-167.

Konig, J. F. R. \& Klippel, R. C. (1963) The Rat Brain: A Stereotaxic Atlas of the Forebrain and Lower Parts of the Brain Stem. Williams \& Wilkins, Baltimore.

Labhsetwar, A. P. \& Zolovick, A. (1973) Evidence for hypothalamic interaction between prostaglandins and catecholamines in promoting gonadotropin secretion for ovulation. Nature, New Biol. 249, 55-56.

Meyer, R. K., Karavolas, H., Klausing, M. \& Norgard, D. (1971) Blood progesterone and pregnenolone levels during phenobarbital (PB) block of PMS-induced ovulation in immature rats. Endocrinology, 88, 983-990.

NeilL, J. D. (1970) Effect of "stress" on serum prolactin and luteinizing hormone levels during the estrous cycle of the rat. Endocrinology, 87, 1192-1197. 